OPEN ACCESS

Edited by:

Denis Gris,

Université de Sherbrooke, Canada

Reviewed by:

Natalia Jimeno,

University of Valladolid, Spain Huei-Kai Huang,

Hualien Tzu Chi Hospital, Taiwan

*Correspondence:

Shang-Hung Chang

afen.chang@gmail.com

${ }^{\dagger}$ These authors have contributed equally to this work

Specialty section:

This article was submitted to Neuroinflammation and Neuropathy, a section of the journal

Frontiers in Aging Neuroscience

Received: 08 October 2021 Accepted: 10 January 2022

Published: 04 February 2022

Citation:

Chang $K-H$, Chen $C-M$,

Wang $C-L$, Tu H-T, Huang $Y-T$, Wu H-C, Chang $\mathrm{C}-\mathrm{H}$ and Chang S-H (2022) Major Bleeding Risk in Patients

With Non-valvular Atrial Fibrillation

Concurrently Taking Direct Oral

Anticoagulants and Antidepressants.

Front. Aging Neurosci. 14:791285.

doi: 10.3389/fnagi.2022.791285

\section{Major Bleeding Risk in Patients With Non-valvular Atrial Fibrillation Concurrently Taking Direct Oral Anticoagulants and Antidepressants}

\author{
Kuo-Hsuan Chang ${ }^{1,2 t}$, Chiung-Mei Chen ${ }^{1,2 t}$, Chun-Li Wang ${ }^{2,3}$, Hui-Tzu Tư ${ }^{4}$ \\ Yu-Tung Huang ${ }^{4}$, Hsiu-Chuan Wu ${ }^{1,2}$, Chien-Hung Chang ${ }^{1,2}$ and Shang-Hung Chang ${ }^{2,3,4,5 *}$ \\ 'Department of Neurology, Chang Gung Memorial Hospital, Linkou Medical Center, Taoyuan, Taiwan, ${ }^{2}$ College of Medicine, \\ Chang Gung University, Taoyuan, Taiwan, ${ }^{3}$ Division of Cardiology, Department of Internal Medicine, Chang Gung Memorial \\ Hospital, Linkou Medical Center, Taoyuan, Taiwan, ${ }^{4}$ Center for Big Data Analytics and Statistics, Chang Gung Memorial \\ Hospital, Linkou Medical Center, Taoyuan, Taiwan, ${ }^{5}$ Graduate Institute of Nursing, Chang Gung University of Science \\ and Technology, Taoyuan, Taiwan
}

Direct oral anticoagulants (DOACs) are commonly prescribed with antidepressants that may increase bleeding risk. Here we assessed the association between DOACs with and without concurrent antidepressants and major bleeding risk in patients with atrial fibrillation (AF) by a retrospective cohort study included patients with AF who received prescriptions of DOACs in Taiwan's National Health Insurance database between 2012 and 2017. Adjusted rate ratio (ARR) of major bleeding was calculated by comparing incidence rate adjusted with Poisson regression and inverse probability of treatment weighting using the propensity score between patient-times with and without antidepressants. Among 98863 patients with AF, concurrent use of bupropion with DOACs increased the risks of all major bleeding (ARR: 1.49, 95\% Cl: $1.02-$ 2.16) and gastrointestinal hemorrhage (ARR: 1.57, 95\% Cl: 1.04-2.33). An increased risk of intracerebral hemorrhage $(\mathrm{ICH})$ was associated with the combinations of DOACs with selective serotonin reuptake inhibitors (SSRIs, ARR: 1.38, 95\% Cl: 1.08-1.76), particularly in paroxetine (ARR: $2.11,95 \% \mathrm{Cl}: 1.17-3.81$ ), and tetracyclic antidepressants (TeCAs, ARR: 1.34, 95\% Cl: 1.01-1.78). In subgroup analyses stratified by individual NOACs, SSRIs increased the risk of $\mathrm{ICH}$ in the dabigatran-treated patients (ARR: 1.55, 95\% Cl: 1.04-2.33). The combinations of apixaban and serotoninnorepinephrine reuptake inhibitors (SNRIs) were associated with a higher risk of all major bleeding (ARR: 1.63, 95\% Cl: 1.04-2.55). These results clearly indicate the drug-drug interactions between DOACs and antidepressants, which should be carefully considered when prescribing DOACs in adult patients. Careful monitoring for bleeding should be performed while concurrently prescribing DOACs with bupropion, SSRI, SNRI, and TeCA. Concomitant use of DOACs and TCAs may be a relatively safe strategy for patients with AF.

Keywords: direct oral anticoagulants, antidepressants, atrial fibrillation, intracerebral hemorrhage, gastrointestinal bleeding 


\section{INTRODUCTION}

Atrial fibrillation (AF) is a prominent cause of ischemic stroke, and oral anticoagulation is frequently indicated for stroke prevention in patients with non-valvular AF (Rasmussen et al., 2012). Direct antagonist oral anticoagulants (DOACs) and warfarin are indicated for the prevention of stroke and systemic embolism in AF and for the treatment of venous thromboembolism (Zirlik and Bode, 2017). Over the past few years, four DOACs, apixaban, rivaroxaban, dabigatran, and edoxaban, have been shown to offer several advantages over warfarin (Yeh et al., 2015). These DOACs have a rapid onset of therapeutic action, shorter half-life, and predictable pharmacodynamic effects; and do not require routine laboratory monitoring (Mekaj et al., 2015). However, DOACs still pose clinically relevant bleeding risks, especially in patients with multiple comorbidities, those with polypharmacy, or those using high-risk medications (Chang et al., 2017). Significant drugdrug interactions are more likely to occur when DOACs are co-administered with medications that change the activity of the multidrug efflux transporter permeability glycoprotein (P-gp) or cytochrome P450 3A4 (CYP3A4) system (Steffel et al., 2018). Medications that inhibit CYP3A4 or P-gp activities, such as amiodarone and fluconazole, may increase DOAC levels and the bleeding risk (Chang et al., 2017; Wang et al., 2020). Avoidance of concurrent prescribing of these medications with DOACs would be necessary for patients with high risk of bleeding.

Depression, a common mental illness in the patients with stroke, is associated with an increased disability, increased cognitive impairment, increased mortality, and worse rehabilitation outcome (Gillen et al., 2001; House et al., 2001; Pohjasvaara et al., 2001; Halperin and Reber, 2007). Antidepressants, such as selective serotonin reuptake inhibitors (SSRIs), selective serotonin-norepinephrine reuptake inhibitors (SNRIs), tricyclic antidepressants (TCAs), and tetracyclic antidepressants (TeCAs), are widely used in the treatment of depression, especially among patients with stroke (El Husseini et al., 2012). However, these medications may affect platelet function, increasing the risk of bleeding (Verdel et al., 2011). For example, SSRIs reduce the ability of platelets to aggregate and increase the risk of bleeding (Skop and Brown, 1996). Clinically, exposure to SSRIs is also associated with an increased risk of gastrointestinal and intracerebral hemorrhage (ICH) (de Abajo et al., 1999; Dalton et al., 2003; Meijer et al., 2004; Hackam and Mrkobrada, 2012). The odds ratios of gastrointestinal hemorrhage in patients taking SSRIs varied from 1.38 to 3.60 (de Abajo et al., 1999; Dalton et al., 2003; Meijer et al., 2004). A meta-analysis also showed the increased rate ratio (1.42) of ICH in patients taking SSRIs (Hackam and Mrkobrada, 2012). Of note, many antidepressants interact with P-gp and CYP3A4 as substrates or inhibitors (DeVane et al., 2004; O'Brien et al., 2012). An in vitro study has demonstrated that paroxetine is a substrate of P-gp (Weiss et al., 2003). Co-administration of a P-gp inhibitor, itraconazole, increases the plasma concentration of paroxetine (Yasui-Furukori et al., 2007). Norfluoxetine, the metabolite of fluoxetine, has an inhibitory effect on CYP3A4 (Weiss et al., 2003). However, little is known regarding the clinical relevance of these drug-drug interactions. Previous studies to explore the effects of antidepressants on bleeding risk in patients taking DOACs also demonstrate conflict results (Sheikh Rezaei et al., 2019; Komen et al., 2020; Marchena et al., 2020). To address this important question, we conducted a nationwide retrospective cohort study to compare the major bleeding risk of patients with AF concurrently treated with DOACs and antidepressants and those who took DOACs alone.

\section{MATERIALS AND METHODS}

\section{Research Ethics}

This retrospective cohort study was approved by the Institutional Review Board of Chang Gung Memorial Hospital, Linkou, Taiwan and complied fully with existing national ethical and regulatory guidelines (ethical license no: 201901357B0). The need to provide written informed consent was waived by the ethics committee because all data were anonymized by the Taiwan National Health Insurance (NHI) Administration.

\section{Data Source}

The data of patients were retrieved from the NHI Research Database and included outpatient, inpatient, and prescription records accessed through the Applied Health and Welfare Data Science Center, Ministry of Health and Welfare in Taiwan. Under a single payer system operated by the Taiwanese government, NHI covered $99 \%$ of Taiwan's population. After the billing process, the National Health Research Institutes (NHRI) compiles data from these insurance claims for research purposes. All identifying information was encrypted. Diagnoses/procedures were identified using International Classification of Diseases, 9th Revision, Clinical Modification (ICD-9-CM) codes from 1997 to 2015 and International Classification of Diseases, 10th Revision, Clinical Modification (ICD-10-CM) codes since 2016.

\section{Study Population}

All patients (outpatients and/or inpatients) with 2 or more consecutive records of AF diagnosis (ICD-9-CM code 427.31 or ICD-10-CM code I48) and DOAC (dabigatran, rivaroxaban, apixaban, or edoxaban) prescriptions for more than 28 days from June 1, 2012, to December 31, 2017, were included. The index date was defined as the first DOAC prescription. Patients were excluded if they took DOACs for indications other than AF, including pulmonary embolism, deep vein thrombosis, mitral stenosis, joint replacement, or valvular surgery within 6 months before the index date, had end-stage renal disease, or were aged less than 30 years or greater than 105 years. Patients were followed up until death, withdrawal from the NHI, or the end of the study period (December 31, 2017).

\section{Follow-Up of Patients}

We divided each calendar year into 4 quarters for each patient. The analytic unit was one person-quarter. Personquarters were used because medications for chronic illnesses were refilled with a maximum length of 3 months under the NHI reimbursement policy. Medications and covariates 
were assessed for each person-quarter, which simplified the assessment of the complex prescription pattern of DOACs and concurrent drugs (Supplementary Figure 1). We identified person-quarters exposed to DOACs with or without concurrent medications. Person-quarters fully prescribed with DOACs and/or antidepressants within the indicated quarter were assigned as those exposed to specific medications. The major bleeding risk of person-quarters exposed to DOACs and concurrent antidepressants was compared with person-quarters exposed to DOACs alone. Only antidepressants used by more than 200 patients were enrolled. These antidepressants were further classified as SNRI (duloxetine or venlafaxine), SSRI (citalopram, escitalopram, fluoxetine, paroxetine, or sertraline), TCA (amitriptyline, imipramine, or melitracen), TeCA (mirtazapine or trazodone), and others (agomelatine and bupropion). Person-quarters with concomitant prescriptions of DOACs and warfarin, or two DOACs were excluded. Each antidepressant was calculated separately in person-quarters with multiple antidepressants ( $0.61 \%$ person-quarters).

\section{Major Outcomes}

The primary outcome was major bleeding, which was identified by ICD codes at the emergency department visit with a primary diagnosis of $\mathrm{ICH}$, gastrointestinal or other bleedings including intraspinal, intraocular, retroperitoneal, intra-articular, pericardial, or intramuscular hemorrhage (Table 1 and Supplementary Table 1). Patients with traumatic hemorrhage were excluded.

\section{Covariates}

Demographics, comorbidities, medications, and medical expense for each person-quarter relevant to the first date of enrollment of patients were identified as covariates. Demographics included age, sex, income level, residency, occupation, and number of outpatient visits. The CHA2DS2-VASc score (Lip et al., 2010) and diseases probably related to hemorrhage were also added as covariates (Table 1 and Supplementary Tables 2, 3). Medications probably related to hemorrhage or interacting with DOACs and prescribed longer than 28 days in each person-quarter were also recognized as covariates (Table 2 and Supplementary Table 4).

\section{Propensity Score Weighting}

Confounding by indication from non-random treatment allocation for concurrent medications was a crucial feature when comparing bleeding risk between patients treated with DOACs with and without concurrent antidepressants. This bias was accounted for by the propensity score, which estimated the probability that a patient was prescribed the concurrent antidepressant during a person-quarter. The specific propensity score for each antidepressant was calculated by applying logistic regression to the identified covariates (Tables 1, 2 and Supplementary Tables 2-4) relevant to the first date of the person-quarter. The distribution of propensity scores in each group stratified by DOACs and antidepressants did not present a significant number of outliers indicative of extreme weight (data not shown). Standardized differences were estimated to assess the balance of individual covariates before and after
TABLE 1 | Demographic analysis of patients taking direct oral anticoagulants (DOACs).

\begin{tabular}{|c|c|}
\hline & DOAC users $(n=98863)$ \\
\hline Age (years) (range) & $74.89 \pm 10.32(30-98)$ \\
\hline Male (\%) & $55610(56.25 \%)$ \\
\hline $\mathrm{CHAD}_{2} \mathrm{DS}_{2}$-VASc score (range) & $4.69 \pm 1.83(2-9)$ \\
\hline Anemia (\%) & $15520(15.7 \%)$ \\
\hline Acute pancreatitis (\%) & $1639(1.66 \%)$ \\
\hline Acute appendicitis (\%) & $1601(1.62 \%)$ \\
\hline Cancer (\%) & $14064(14.23 \%)$ \\
\hline Metastatic solid tumor (\%) & $1334(1.35 \%)$ \\
\hline \multicolumn{2}{|l|}{ Cardiovascular diseases } \\
\hline Hypertension (\%) & $86688(87.68 \%)$ \\
\hline Myocardial infarction (\%) & 6507 (6.58\%) \\
\hline Congestive heart failure (\%) & 51300 (51.89\%) \\
\hline Peripheral vascular disease (\%) & $13896(14.06 \%)$ \\
\hline Peripheral arterial occlusive disease (\%) & $2677(2.71 \%)$ \\
\hline Percutaneous coronary intervention (\%) & $8660(8.76 \%)$ \\
\hline Coronary artery bypass surgery (\%) & $1121(1.13 \%)$ \\
\hline Chronic kidney disease (\%) & $26568(26.87 \%)$ \\
\hline \multicolumn{2}{|l|}{ Gastrointestinal and hepatic diseases } \\
\hline Peptic ulcer disease (\%) & 56455 (57.10\%) \\
\hline Mild liver disease (\%) & 36580 (37.00\%) \\
\hline Moderate or severe liver disease (\%) & $334(0.34 \%)$ \\
\hline Human immunodeficiency virus infection (\%) & $25(0.03 \%)$ \\
\hline Intestinal obstruction without mention of hernia (\%) & $5147(5.21 \%)$ \\
\hline \multicolumn{2}{|l|}{ Metabolic disease } \\
\hline Diabetes Mellitus (\%) & $41790(42.27 \%)$ \\
\hline Diabetes with complications (\%) & 14745 (14.91\%) \\
\hline \multicolumn{2}{|l|}{ Neurological diseases } \\
\hline Cerebral vascular disease (\%) & 50422 (51.00\%) \\
\hline Ischemic stroke (\%) & $37610(38.04 \%)$ \\
\hline Transient ischemic attack (\%) & 12915 (13.06\%) \\
\hline Hemiplegia and paraplegia (\%) & 5096 (5.15\%) \\
\hline Dementia (\%) & 11427 (11.56\%) \\
\hline Epilepsy (\%) & $2793(2.83 \%)$ \\
\hline
\end{tabular}

inverse probability of treatment weighting using propensity score (Supplementary Tables 5-9). A negligible difference was defined as an absolute standardized mean difference of $<0.1$.

\section{Statistical Analysis}

To account for the intraindividual correlation across personquarters, we used Poisson regression with a generalized estimating equation model to calculate the adjusted incidence rate that considered the inverse probability of treatment weighting by propensity scores if the number of bleeding events was greater than 3. All regression analyses were performed separately for each combination/medication with more than three bleeding events; person-quarters using DOAC alone was used as the reference. To preclude the potentially unmeasured confounders (Lipsitch et al., 2010), we used acute pancreatitis and acute appendicitis as negative control outcomes. To evaluate the potential reverse causality, we performed a sensitivity analysis to remove the bleeding events that occurred within 
TABLE 2 | Medications during follow-up.

\begin{tabular}{|c|c|}
\hline & DOAC users $(n=98863)$ \\
\hline Antibiotics and antifungal drugs & $2800(2.83 \%)$ \\
\hline Anticoagulants & 98863 (100\%) \\
\hline Apixaban & 20825 (21.06\%) \\
\hline Dabigatran & 42779 (43.27\%) \\
\hline Edoxaban & 10517 (10.64\%) \\
\hline Rivaroxaban & 55587 (56.23\%) \\
\hline Antidepressants & 19638 (19.86\%) \\
\hline SNRI & $2087(2.11 \%)$ \\
\hline Duloxetine & $1536(1.55 \%)$ \\
\hline Venlafaxine & $626(0.63 \%)$ \\
\hline SSRI & $7234(7.32 \%)$ \\
\hline Citalopram & 3695 (3.74\%) \\
\hline Escitalopram & $3442(3.48 \%)$ \\
\hline Fluoxetine & $934(0.94 \%)$ \\
\hline Paroxetine & 875 (0.89\%) \\
\hline Sertraline & $2751(2.78 \%)$ \\
\hline TCA & $9591(9.70 \%)$ \\
\hline Amitriptyline & $3183(3.22 \%)$ \\
\hline Imipramine & 6177 (6.25\%) \\
\hline Melitracen & $3183(3.22 \%)$ \\
\hline TeCA & $6149(6.22 \%)$ \\
\hline Mirtazapine & $1656(1.68 \%)$ \\
\hline Trazodone & 4922 (4.98\%) \\
\hline Others & 1179 (1.19\%) \\
\hline Agomelatine & $653(0.66 \%)$ \\
\hline Bupropion & $534(0.54 \%)$ \\
\hline Antiepileptics & 4928 (4.98\%) \\
\hline Antihypertensives & 59324 (60.10\%) \\
\hline Antiplatelets & $24186(24.46 \%)$ \\
\hline Cardiovascular drugs & 36505 (36.92\%) \\
\hline Cyclosporine (\%) & $49(0.05 \%)$ \\
\hline Glucocorticoid (\%) & 7987 (8.08\%) \\
\hline Insulin (\%) & $6236(6.31 \%)$ \\
\hline Lipid lowering drugs & 19172 (19.39\%) \\
\hline Non-steroid anti-inflammatory drugs (\%) & $19180(19.40 \%)$ \\
\hline
\end{tabular}

DOAC, direct oral anticoagulant; SNRI, selective serotonin-norepinephrine reuptake inhibitor; SSRI, selective serotonin reuptake inhibitors; TCA, tricyclic antidepressant; TeCA, tetracyclic antidepressant.

the first person-quarter following prescriptions of DOACs or antidepressants. Patients with missing data $(<0.1 \%$ of DOAC users) were excluded. The analysis was conducted using SAS (SAS Institute), version 9.4

\section{RESULTS}

We identified a total of 98863 patients with AF who received DOAC therapy between June 1, 2012, and December 31, 2017 (Figure 1). The characteristics of the patients at the first date of DOAC prescription are listed in Tables 1, 2 and Supplementary Tables 3, 4. The mean age was $74.89 \pm 10.32$ years, and $56.25 \%$ of the studied population comprised men. The baseline average CHA2DS2-VASc score was $4.69 \pm 1.83$. Hypertension

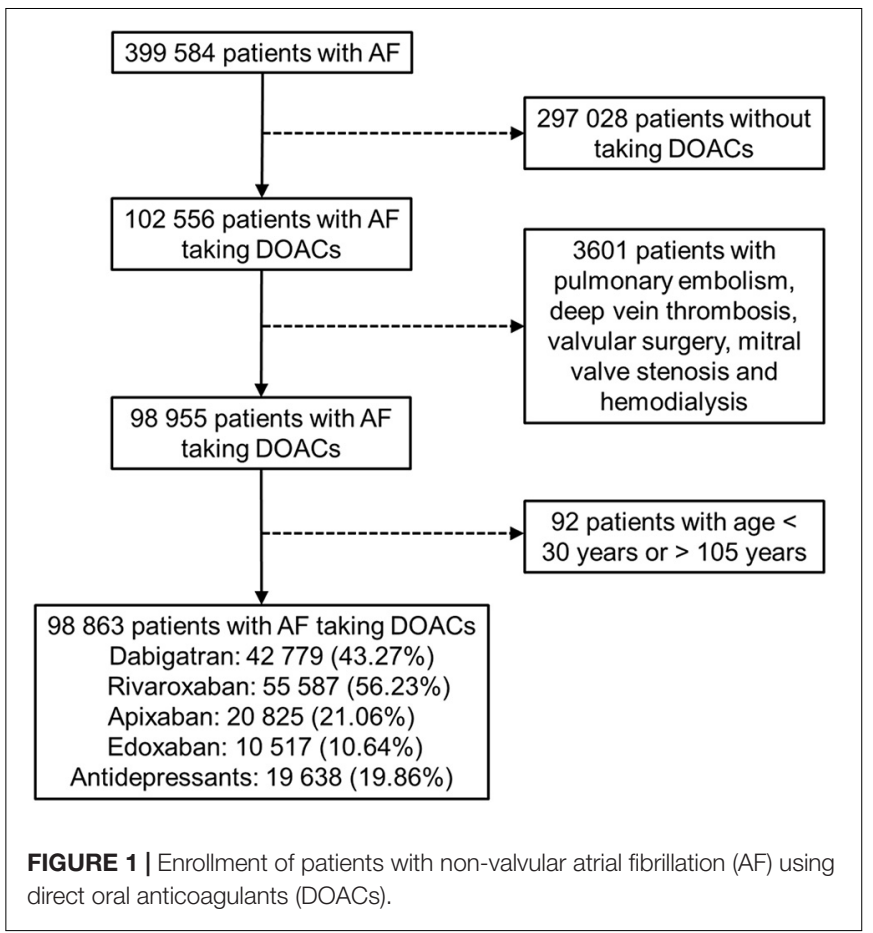

was observed in $87.68 \%$ of the included patients, and congestive heart failure and cerebrovascular disease were noted in $50.89 \%$ and $51.00 \%$ of the included patients, respectively. Diabetes mellitus was diagnosed in $42.27 \%$ of the included patients. A total of 19638 (19.86\%) DOAC-treated patients with AF concurrently used antidepressants (Figure 1). The most common antidepressants prescribed with concurrent DOACs were imipramine (6.25\%), followed by trazodone (4.98\%), citalopram (3.74\%), and escitalopram (3.48\%).

During follow-up, 6297 (6.37\%) patients had one major bleeding events. Multiple major bleeding events occurred in $782(0.80 \%)$ patients. Among 705521 person-quarters with DOAC prescriptions, 8037 (1.14\%) major bleeding events were identified. $71374(10.12 \%)$ person-quarters were prescribed with antidepressants. Multiple antidepressants were prescribed in $4333(0.61 \%)$ person-quarters. Table 3 and Supplementary Table 10 summarized the incidence rate and adjusted incidence rate for major bleeding events among the 14 combinations of a DOAC and an antidepressant. Although there was no subclass of antidepressants increased bleeding risk among the DOACtreated patients with AF, the individual drug analysis showed that the combination of DOACs with bupropion was significantly associated with a higher risk of major bleeding compared with DOACs alone (adjusted rate ratio [ARR]: 1.49, 95\% confidence interval [CI]: 1.02-2.16, $P=0.037$ ). The combinations of DOACs with any of the other antidepressants were not associated with a higher risk of major bleeding. Subgroup analysis by bleeding site revealed an increased risk of ICH associated with the combinations of DOACs with SSRIs (ARR: 1.38, 95\% CI: $1.08-1.76, P=0.010$ ) and TeCA (ARR: 1.34 , 95\% CI: $1.01-$ 1.78, $P=0.041)$ compared with DOACs alone in patients with AF (Table 4 and Supplementary Table 11). Individual 
TABLE 3 | Major bleeding risk among patients with atrial fibrillation (AF) taking DOACs with or without concurrent antidepressants.

\begin{tabular}{|c|c|c|c|c|c|c|c|c|}
\hline $\begin{array}{l}\text { Concurrent } \\
\text { medication }\end{array}$ & $\begin{array}{l}\text { Person-Quarters } \\
\text { with DOAC use }\end{array}$ & $\begin{array}{l}\text { No. of Bleeding } \\
\text { Events }\end{array}$ & \multicolumn{2}{|c|}{$\begin{array}{c}\text { Crude Major Bleeding } \\
\text { Incidence Rate }(95 \% \mathrm{Cl}) \text { per } \\
1000 \text { Person-Years }\end{array}$} & \multicolumn{2}{|c|}{$\begin{array}{c}\text { *Adjusted Incidence } \\
\text { Rate }(95 \% \mathrm{Cl}) \text { per } \\
1000 \text { Person-Years }\end{array}$} & \multicolumn{2}{|c|}{$\begin{array}{c}{ }^{*} \text { Adjusted } \\
\text { Rate Ratio } \\
\text { (95\% Cl) }\end{array}$} \\
\hline With & 6642 & 97 & 58.84 & (47.80-72.43) & 59.25 & $(48.22-72.79)$ & 1.15 & $(0.93-1.42)$ \\
\hline twithout & 698879 & 7940 & 45.93 & (44.83-47.06) & 51.47 & $(49.06-54.01)$ & 1 & \\
\hline \multicolumn{9}{|l|}{ SSRI } \\
\hline With & 25344 & 329 & 51.86 & (46.29-58.09) & 52.47 & $(46.90-58.71)$ & 1.02 & $(0.91-1.15)$ \\
\hline twithout & 680177 & 7708 & 45.83 & (44.72-46.97) & 51.45 & $(49.92-53.01)$ & 1 & \\
\hline \multicolumn{9}{|l|}{ TCA } \\
\hline With & 25083 & 319 & 50.99 & $(45.44-57.21)$ & 51.4 & $(45.84-57.63)$ & 1.02 & $(0.91-1.15)$ \\
\hline twithout & 680438 & 7718 & 45.87 & (44.75-47.01) & 50.38 & $(48.92-51.90)$ & 1 & \\
\hline \multicolumn{9}{|l|}{ TeCA } \\
\hline With & 19179 & 267 & 55.68 & $(49.05-63.21)$ & 56.42 & (49.76-63.98) & 1.07 & $(0.95-1.22)$ \\
\hline twithout & 686342 & 7770 & 45.78 & $(44.67-46.91)$ & 52.51 & (51.03-54.04) & 1 & \\
\hline \multicolumn{9}{|l|}{ Others } \\
\hline With & 3511 & 41 & 47.02 & (34.35-64.36) & 47.44 & (34.79-64.68) & 0.97 & $(0.71-1.33)$ \\
\hline twithout & 702010 & 7996 & 46.04 & (44.94-47.17) & 48.86 & $(47.40-50.36)$ & 1 & \\
\hline \multicolumn{9}{|l|}{ Bupropion } \\
\hline With & 1457 & 26 & 71.61 & $(49.25-104.11)$ & 71.8 & $(49.55-104.04)$ & $\# 1.49$ & $(1.02-2.16)$ \\
\hline twithout & 704064 & 8011 & 46 & (44.90-47.12) & 48.33 & (46.75-49.97) & 1 & \\
\hline
\end{tabular}

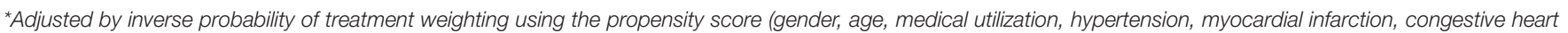

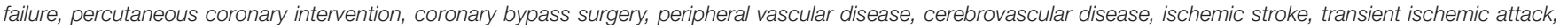

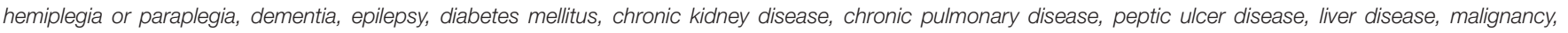

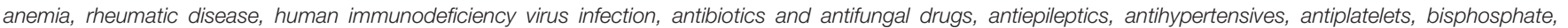
cardiovascular drugs, cyclosporine, glucocorticoid, insulin, lipid lower drugs, non-steroid anti-inflammatory drugs, residence, income level, and occupation; see Tables 1, 2 and Supplementary Tables 2-4).

† "Without" indicates DOACs alone.

$\# P<0.05$, compared with DOACs alone.

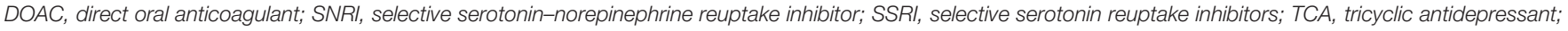
TeCA, tetracyclic antidepressant.

drug analysis determined that the combination of paroxetine (ARR: $2.11,95 \% \mathrm{CI}: 1.17-3.81, P=0.013$ ) with DOACs in the patients with AF were associated with a higher risk of $\mathrm{ICH}$ compared with DOACs alone. Bupropion increased the risk of gastrointestinal hemorrhage in the DOAC-treated patients with AF (ARR: 1.57, 95\% CI: 1.04-2.35, $P=0.031$, Table 5 and Supplementary Table 12). None of the antidepressants were associated with a high risk of intraspinal, intraocular, retroperitoneal, intra-articular, pericardial, or intramuscular hemorrhage (Supplementary Table 13). Separate analyses showed that SSRIs increased the risk of ICH in the dabigatrantreated patients with AF (ARR: $1.55,95 \%$ CI: 1.04-2.33, $P=0.033$, Table 6 and Supplementary Table 14). The combinations of apixaban and SNRIs were associated with a higher risk of major bleeding (ARR: 1.63, 95\% CI: 1.04-2.55, $P=0.032$, Table 6 and Supplementary Table 15). None of antidepressants increased the risk of bleeding in AF patients treated with rivaroxaban (Supplementary Table 16). Because edoxaban was introduced in Taiwan after 2016, we did not include it in the separate analysis.

None of the combinations were associated with a high risk of unrelated events as negative control outcomes, such as acute pancreatitis or acute appendicitis (Supplementary Table 17). The results of evaluating the potential reverse causality by removing the bleeding events that occurred within the first person-quarter was similar to the main findings (Supplementary Table 18).

\section{DISCUSSION}

This nationwide population-based cohort study determined that bupropion was associated with a significantly increased risk of major bleeding, particularly gastrointestinal bleeding. SSRIs, particularly paroxetine, and TeCAs were associated with a significantly increased risk of ICH. Bleeding risk varied among DOACs. In AF patients taking dabigatran, SSRIs also increased the risk of ICH. SNRIs were associated with an increased risk of major bleeding in apixaban-treated AF patients. TCAs were not associated with an increased risk of any major bleeding. Concomitant use of DOACs and TCAs may be a relatively safe strategy for patients with AF.

Our results uncovered an association between bupropion and an increased risk of major bleeding and gastrointestinal hemorrhage in the patients with AF taking DOACs. Bupropion is a potent inhibitor of CYP2D6 (Kotlyar et al., 2005), whereas its effect on CYP3A4 remains uncertain. An in vitro study demonstrated that bupropion and its metabolites exhibited only little affinity for P-gp (Wang et al., 2008). Therefore, 
TABLE 4 | Risk of intracerebral hemorrhage among patients with AF taking DOACs with or without concurrent antidepressants.

\begin{tabular}{|c|c|c|c|c|c|c|c|c|}
\hline \multirow{2}{*}{$\begin{array}{l}\text { Concurrent } \\
\text { medication }\end{array}$} & \multirow[t]{2}{*}{$\begin{array}{l}\text { Person- Quarters } \\
\text { with DOAC use }\end{array}$} & \multirow[t]{2}{*}{$\begin{array}{l}\text { No. of Bleeding } \\
\text { Events }\end{array}$} & \multicolumn{2}{|c|}{$\begin{array}{c}\text { Crude Major Bleeding } \\
\text { Incidence Rate }(95 \% \mathrm{Cl}) \text { per } \\
1000 \text { Person-Years }\end{array}$} & \multicolumn{2}{|c|}{$\begin{array}{l}{ }^{*} \text { Adjusted Incidence } \\
\text { Rate }(95 \% \text { Cl) per } \\
1000 \text { Person-Years }\end{array}$} & \multicolumn{2}{|c|}{$\begin{array}{c}{ }^{\star} \text { Adjusted } \\
\text { Rate Ratio } \\
(95 \% \mathrm{Cl})\end{array}$} \\
\hline & & & & & & & & \\
\hline With & 6642 & 14 & 8.68 & $(5.16-14.59)$ & 8.55 & $(5.07-14.44)$ & 1.1 & $(0.65-1.87)$ \\
\hline twithout & 698879 & 1250 & 7.23 & (6.83-7.66) & 7.78 & (7.21-8.39) & 1 & \\
\hline \multicolumn{9}{|l|}{ SSRI } \\
\hline With & 25344 & 75 & 11.87 & $(9.39-15.00)$ & 12.01 & $(9.52-15.15)$ & \#1.38 & $(1.08-1.76)$ \\
\hline twithout & 680177 & 1189 & 7.07 & $(6.67-7.51)$ & 8.73 & $(8.09-9.41)$ & 1 & \\
\hline \multicolumn{9}{|l|}{ TCA } \\
\hline With & 25083 & 54 & 8.69 & $(6.66-11.34)$ & 8.66 & $(6.64-11.30)$ & 1.18 & $(0.90-1.55)$ \\
\hline without & 680438 & 1210 & 7.19 & (6.78-7.63) & 7.33 & (6.88-7.82) & 1 & \\
\hline \multicolumn{9}{|l|}{ TeCA } \\
\hline With & 19179 & 52 & 10.88 & $(8.24-14.36)$ & 10.94 & $(8.30-14.42)$ & \#1.34 & $(1.01-1.78)$ \\
\hline twithout & 686342 & 1212 & 7.15 & (6.74-7.58) & 8.15 & $(7.61-8.72)$ & 1 & \\
\hline \multicolumn{9}{|l|}{ Others } \\
\hline With & 3511 & 5 & 5.71 & $(2.34-13.94)$ & 5.79 & $(2.41-13.91)$ & 0.71 & $(0.29-1.71)$ \\
\hline twithout & 702010 & 1259 & 7.26 & $(6.85-7.69)$ & 8.18 & $(7.56-8.85)$ & 1 & \\
\hline \multicolumn{9}{|l|}{ Paroxetine } \\
\hline With & 2601 & 11 & 16.95 & $(9.45-30.39)$ & 16.9 & $(9.41-30.36)$ & \#2.11 & $(1.17-3.81)$ \\
\hline twithout & 702920 & 1253 & 7.21 & (6.81-7.64) & 8 & $(7.43-8.61)$ & 1 & \\
\hline
\end{tabular}

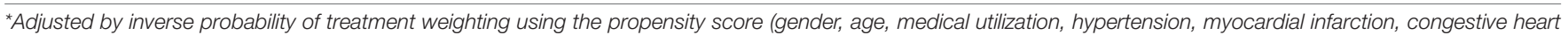

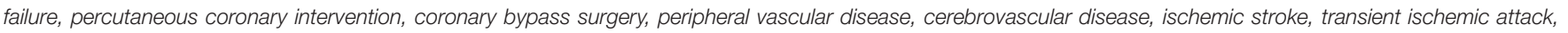

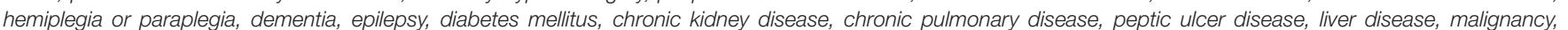

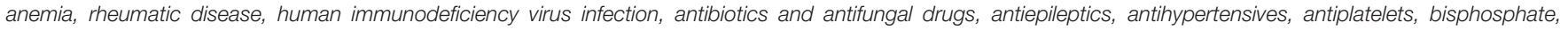
cardiovascular drugs, cyclosporine, glucocorticoid, insulin, lipid lower drugs, non-steroid anti-inflammatory drugs, residence, income level, and occupation; see Tables 1, 2 and Supplementary Tables 2-4).

† "Without" indicates DOAC alone.

$\# P<0.05$, compared with DOAC alone.

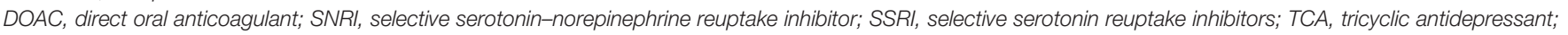
TeCA, tetracyclic antidepressant.

the mechanism of these associations remains elusive. Of note, bupropion have been linked to cases of hepatic injury, which could increase the risk of bleeding (Voican et al., 2014). An unknown drug-drug interaction by polypharmacy in patients with AF may also contribute to the increased risk of bleeding. Careful monitoring for bleeding would be necessary in patients with AF concomitantly taking DOACs and bupropion.

The association between ICH and SSRIs has been demonstrated in several observational studies (Hackam and Mrkobrada, 2012; Renoux et al., 2017). Serotonin stored in platelets represents more than $99 \%$ of the total serotonin concentration in the human body (Li et al., 1997). After vascular injury and platelet activation, serotonin is released into the bloodstream and binds to specific receptors to promote vasoconstriction and platelet aggregation and thereby hemostasis (Li et al., 1997). Reuptake of serotonin into platelets involves a serotonin transporter that is blocked by SSRIs (Halperin and Reber, 2007). This inhibition would in turn reduce the potential for platelet aggregation and therefore platelet thrombus formation, with a subsequent increased risk of bleeding. SSRIs with a larger degree of serotonin reuptake inhibition have been more frequently associated with abnormal bleeding and modification of hemostasis markers (Halperin and Reber, 2007). The risk of ICH in patients exposed concurrently to anticoagulants and SSRIs has not been extensively explored. In a case-control study, SSRIs and warfarin did not confer an increased risk of ICH compared with warfarin alone (Kharofa et al., 2007). Our study demonstrated a higher risk of ICH in the patients with AF concurrently taking DOACs and SSRIs compared with those taking DOACs alone. The individual drug analysis identified associations between paroxetine and an increased risk of ICH in this patient group. Notably, paroxetine demonstrates a high degree of serotonin reuptake inhibition (Tatsumi et al., 1997; Renoux et al., 2017) and could be a substrate of CYP3A4 and P-gp (Cozza et al., 2003; O’Brien et al., 2012). The competitive binding to CYP3A4 by paroxetine may enhance the effect of DOACs. However, P-gp-mediated drug efflux at the blood-brain barrier may limit drug delivery to the brain (Loscher and Potschka, 2005). Competitive binding to P-gp by DOACs may prevent the drug efflux by P-gp at the blood-brain barrier and increase the brain concentration of these SSRIs, leading to an increased risk of ICH.

Separated drug analysis further showed that SSRIs increased risk of $\mathrm{ICH}$ in AF patients taking dabigatran. Dabigatran is one of the most frequently involved drugs for the occurrence of drug adverse-effects (Shehab et al., 2016). Dabigatran is contraindicated with potent $\mathrm{P}$-gp inhibitors such as ketoconazole, ciclosporin, itraconazole or dronedarone $(\mathrm{GmbH}, 2020)$. The blood concentration of dabigatran is increased by about 2.4fold and 2.3-fold when dabigatran is co-administered with dronedarone $(\mathrm{GmbH}, 2020)$, which may increase the bleeding risk (Reilly et al., 2014; Sinigoj et al., 2015). Our study also 
TABLE 5 | Risk of gastrointestinal hemorrhage among patients with AF taking DOACs with or without concurrent antidepressants.

\begin{tabular}{|c|c|c|c|c|c|c|c|c|}
\hline $\begin{array}{l}\text { Concurrent } \\
\text { medication }\end{array}$ & \multirow[t]{2}{*}{$\begin{array}{l}\text { Person- Quarters } \\
\text { with DOAC use }\end{array}$} & \multirow[t]{2}{*}{$\begin{array}{l}\text { No. of Bleeding } \\
\text { Events }\end{array}$} & \multicolumn{2}{|c|}{$\begin{array}{c}\text { Crude Major Bleeding } \\
\text { Incidence Rate }(95 \% \mathrm{CI}) \text { per } \\
1000 \text { Person-Years }\end{array}$} & \multicolumn{2}{|c|}{$\begin{array}{l}{ }^{*} \text { Adjusted Incidence } \\
\text { Rate }(95 \% \mathrm{Cl}) \text { per } \\
1000 \text { Person-Years }\end{array}$} & \multicolumn{2}{|c|}{$\begin{array}{c}{ }^{\star} \text { Adjusted } \\
\text { Rate Ratio } \\
(95 \% \mathrm{Cl})\end{array}$} \\
\hline & & & & & & & & \\
\hline With & 6642 & 79 & 47.68 & $(37.76-60.21)$ & 48.18 & $(38.27-60.67)$ & 1.15 & $(0.90-1.45)$ \\
\hline twithout & 698879 & 6411 & 37.03 & (36.04-38.06) & 42.05 & (39.73-44.51) & 1 & \\
\hline \multicolumn{9}{|l|}{ SSRI } \\
\hline With & 25344 & 248 & 39 & $(34.20-44.48)$ & 39.47 & $(34.66-44.95)$ & 0.96 & $(0.84-1.10)$ \\
\hline twithout & 680177 & 6242 & 37.06 & $(36.06-38.10)$ & 41.06 & $(39.70-42.46)$ & 1 & \\
\hline \multicolumn{9}{|l|}{ TCA } \\
\hline With & 25083 & 260 & 41.42 & $(36.38-47.15)$ & 41.85 & $(36.80-47.59)$ & 1.01 & $(0.89-1.15)$ \\
\hline without & 680438 & 6230 & 36.98 & (35.97-38.01) & 41.4 & $(40.02-42.82)$ & 1 & \\
\hline \multicolumn{9}{|l|}{ TeCA } \\
\hline With & 19179 & 206 & 42.93 & (37.22-49.51) & 43.46 & $(37.74-50.06)$ & 1.02 & $(0.88-1.17)$ \\
\hline without & 686342 & 6284 & 36.97 & $(35.97-38.00)$ & 42.73 & $(41.38-44.13)$ & 1 & \\
\hline \multicolumn{9}{|l|}{ Others } \\
\hline With & 3511 & 36 & 41.34 & $(29.55-57.84)$ & 41.59 & $(29.84-57.97)$ & 1.07 & $(0.76-1.49)$ \\
\hline without & 702010 & 6454 & 37.11 & $(36.12-38.14)$ & 39 & (37.72-40.33) & 1 & \\
\hline \multicolumn{9}{|l|}{ Bupropion } \\
\hline With & 1457 & 22 & 60.23 & (39.94-90.84) & 60.65 & $(40.47-90.89)$ & $\# 1.57$ & $(1.04-2.35)$ \\
\hline without & 704064 & 6468 & 37.09 & (36.09-38.11) & 38.74 & $(37.29-40.25)$ & 1 & \\
\hline
\end{tabular}

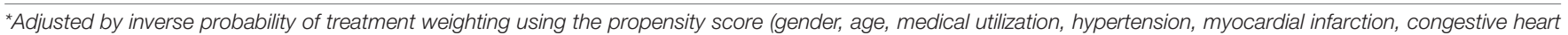

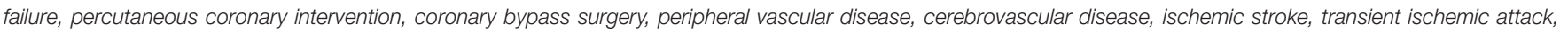

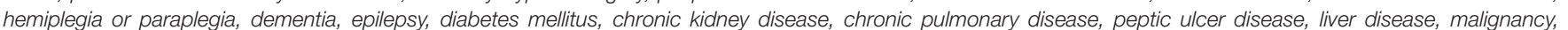

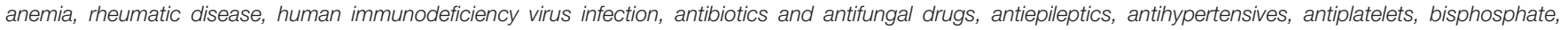
cardiovascular drugs, cyclosporine, glucocorticoid, insulin, lipid lower drugs, non-steroid anti-inflammatory drugs, residence, income level, and occupation; see Tables 1, 2 and Supplementary Tables 2-4).

† "Without" indicates DOACs alone.

$\# P<0.05$, compared with DOACs alone.

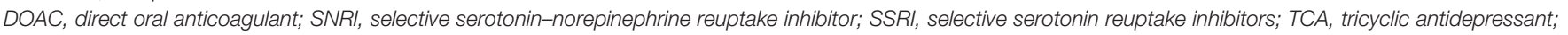
TeCA, tetracyclic antidepressant.

showed the increased risk of major bleedings when concurrent use of apixaban with SNRIs compared with apixaban alone. Not only serve as CYP3A4 substrates, apixaban are also metabolized by P-gp (Steffel et al., 2018). Concomitant use of rifampin, an inducer of CYP3A4 and P-gp, decreases blood concentration of apixaban by $50 \%$ (Squibb, 2021). However, the data for the inhibitors of CYP3A4 and P-gp remain insufficient. Given that both duloxetine and venlafaxine inhibit P-gp activities, it is reasonable to propose that concurrently use of apixaban and SNRIs may increase the concentration of apixaban as well as bleeding risk. More pharmacokinetics and clinical studies regarding interactions between individual DOACs and antidepressants will be warranted to confirm these findings.

An increased risk of ICH was observed in AF patients with DOACs concurrently taking TeCAs. Although metabolized by CYP3A4 (Rotzinger et al., 1998), trazodone only weakly inhibits the activity of CYP3A4 (Caccia, 2007). Mirtazapine may not affect the activity of CYP3A4 as well (Anttila and Leinonen, 2001). In cell culture, trazodone may induce expression of intestinal P-gp, leading to the reduced absorption of co-administered oral medications (Störmer et al., 2001). Mirtazapine is not a substrate of P-gp (O’Brien et al., 2012). Administration with mirtazapine to P-gp knockout mice is not affect its concentration in brain (O'Brien et al., 2012). Further studies will be warranted to clarify the mechanisms of TeCAs in the increased ICH risk of these patients.
Tricyclic antidepressants do not appear to increase bleeding risk when used alone (de Abajo et al., 1999; Schalekamp et al., 2008). However, they could potentially increase the bleeding risk with warfarin through their inhibitory effects on warfarin metabolism. In rats, amitriptyline demonstrated a dosedependent increase in prothrombin time, which correlated with an increase in the plasma half-life of warfarin (Loomis and Racz, 1980). However, a case-control study determined that the administration of TCAs and coumarin did not confer a higher risk of gastrointestinal bleeding compared with coumarin alone (Schalekamp et al., 2008). Our results indicate that, as a class, TCA is not associated with any major bleeding in the patients with AF taking DOACs.

This study has some limitations. Misclassification bias may become an issue in the nationwide registration studies, although large data sets could potentially overcome this problem. Studies to evaluate the validity of diagnosis codes in the NHI research database also showed modest to high sensitivity and positive predictive values in epilepsy (Chen et al., 2012), ischemic stroke (Hsieh et al., 2015), hypertension, diabetes, hyperlipidemia and atrial fibrillation (Sung et al., 2016). Laboratory data regarding renal or liver function were not available in the dataset. Thus, the results may have been biased by unmeasured confounders. However, these biases were minimized by incorporating an extensive list of covariates that represent proximal indicators representing the severity of renal or liver disease and other 
TABLE 6 | Risk of major bleeding among patients with AF taking dabigatran/apixaban with or without concurrent antidepressants.

\begin{tabular}{|c|c|c|c|c|c|c|c|c|}
\hline \multirow{3}{*}{\begin{tabular}{l}
$\begin{array}{l}\text { Concurrent } \\
\text { medication }\end{array}$ \\
\multicolumn{1}{r}{ Major } \\
SNRI
\end{tabular}} & \multirow{2}{*}{$\begin{array}{c}\text { Person- Quarters with } \\
\text { DOAC use } \\
\text { ing (Dabigatran) }\end{array}$} & \multirow[t]{3}{*}{ No. of Bleeding Events } & \multirow{2}{*}{\multicolumn{2}{|c|}{$\begin{array}{c}\text { Crude Major Bleeding } \\
\text { Incidence Rate }(95 \% \mathrm{Cl}) \text { per } \\
1000 \text { Person-Years }\end{array}$}} & & \\
\hline & & & & & \multicolumn{2}{|c|}{$\begin{array}{c}{ }^{\star} \text { Adjusted Incidence } \\
\text { Rate }(95 \% \mathrm{Cl}) \text { per } 1000 \\
\text { Person-Years }\end{array}$} & \multicolumn{2}{|c|}{$\begin{array}{l}\text { *Adjusted Rate } \\
\text { Ratio }(95 \% \mathrm{Cl})\end{array}$} \\
\hline & & & & & & & & \\
\hline with & 2665 & 39 & 59.57 & $(43.42-81.72)$ & 59.13 & $(43.14-81.04)$ & 1.32 & $(0.96-1.83)$ \\
\hline twithout & 267899 & 2678 & 40.49 & $(38.87-42.17)$ & 44.64 & $(41.81-47.66)$ & 1 & \\
\hline \multicolumn{9}{|l|}{ SSRI } \\
\hline with & 9680 & 119 & 49.27 & $(40.70-59.65)$ & 49.77 & $(41.17-60.17)$ & 1.09 & $(0.90-1.32)$ \\
\hline twithout & 260884 & 2598 & 40.35 & $(38.72-42.05)$ & 45.77 & (43.58-48.08) & 1 & \\
\hline \multicolumn{9}{|l|}{ TCA } \\
\hline with & 10242 & 116 & 45.58 & $(37.80-54.96)$ & 45.65 & (37.87-55.03) & 1.05 & $(0.86-1.27)$ \\
\hline twithout & 260322 & 2601 & 40.48 & $(38.84-42.18)$ & 43.61 & $(41.64-45.68)$ & 1 & \\
\hline \multicolumn{9}{|l|}{ TeCA } \\
\hline with & 7252 & 98 & 54.2 & $(43.76-67.12)$ & 54.62 & $(44.16-67.57)$ & 1.19 & $(0.95-1.47)$ \\
\hline twithout & 263312 & 2619 & 40.3 & $(38.68-41.98)$ & 46.09 & $(43.90-48.39)$ & 1 & \\
\hline \multicolumn{9}{|l|}{ Others } \\
\hline with & 1293 & 12 & 36.75 & (20.00- 67.54) & 37.44 & (20.56- 68.19) & 0.9 & $(0.49-1.65)$ \\
\hline twithout & 269271 & 2705 & 40.69 & (39.08-42.38) & 41.48 & $(39.31-43.78)$ & 1 & \\
\hline \multicolumn{9}{|c|}{ Intracerebral hemorrhage (Dabigatran) } \\
\hline \multicolumn{9}{|l|}{ SSRI } \\
\hline with & 9680 & 26 & 10.78 & $(7.31-15.90)$ & 10.9 & $(7.41-16.03)$ & $\# 1.55$ & $(1.04-2.33)$ \\
\hline †without & 260884 & 364 & 5.64 & $(5.07-6.26)$ & 7.01 & $(6.15-8.00)$ & 1 & \\
\hline \multicolumn{9}{|c|}{ Major bleeding (Apixaban) } \\
\hline \multicolumn{9}{|l|}{ SNRI } \\
\hline with & 813 & 19 & 95.03 & $(61.46-146.94)$ & 94.32 & $(60.87-146.17)$ & $\# 1.63$ & $(1.04-2.55)$ \\
\hline twithout & 89336 & 1079 & 49.05 & $(46.00-52.30)$ & 57.76 & $(50.47-66.11)$ & 1 & \\
\hline \multicolumn{9}{|l|}{ SSRI } \\
\hline with & 3385 & 44 & 52.39 & $(38.97-70.42)$ & 52.48 & $(39.14-70.36)$ & 0.95 & $(0.70-1.28)$ \\
\hline twithout & 86764 & 1054 & 49.34 & $(46.24-52.65)$ & 55.52 & (51.12-60.29) & 1 & \\
\hline \multicolumn{9}{|l|}{ TCA } \\
\hline with & 3127 & 43 & 55.22 & $(40.63-75.05)$ & 55.57 & $(41.01-75.30)$ & 1.1 & $(0.80-1.50)$ \\
\hline twithout & 87022 & 1055 & 49.25 & $(46.15-52.55)$ & 50.74 & $(47.19-54.55)$ & 1 & \\
\hline \multicolumn{9}{|l|}{ TeCA } \\
\hline with & 2477 & 39 & 63.62 & $(45.97-88.03)$ & 63.74 & (46.04-88.23) & 1.12 & $(0.80-1.57)$ \\
\hline twithout & 87672 & 1059 & 49.06 & $(45.98-52.33)$ & 56.75 & $(52.43-61.43)$ & 1 & \\
\hline \multicolumn{9}{|l|}{ Others } \\
\hline with & 511 & 6 & 46.19 & $(20.27-105.24)$ & 47.32 & (21.32-105.02) & 0.86 & $(0.39-1.92)$ \\
\hline twithout & 89638 & 1092 & 49.47 & $(46.41-52.73)$ & 54.93 & $(50.03-60.31)$ & 1 & \\
\hline
\end{tabular}

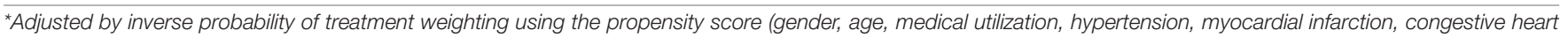

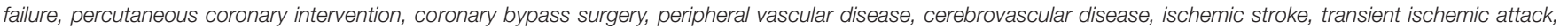

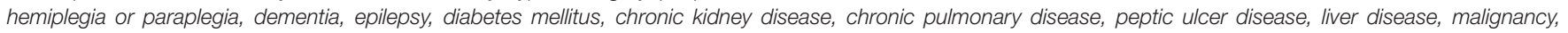

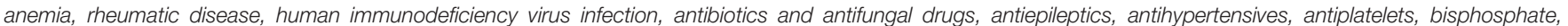
cardiovascular drugs, cyclosporine, glucocorticoid, insulin, lipid lower drugs, non-steroid anti-inflammatory drugs, residence, income level, and occupation; see Tables 1, 2 and Supplementary Tables 2-4).

†"Without" indicates dabigatran or apixaban alone.

$\# P<0.05$, compared with dabigatran or apixaban alone.

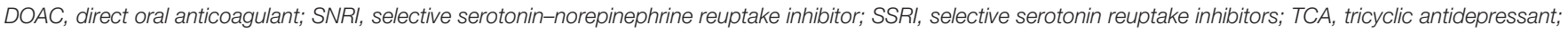

TeCA, tetracyclic antidepressants.

clinical factors typically considered by clinicians prescribing DOACs. Other drugs, such as lipid-lowering drugs, antiplatelets or non-steroid anti-inflammatory drugs, may influence bleeding risk, although an extensive adjustment in medications has been performed in our model. Around 30\% of patients with hypertension in our population did not receive pharmacological treatment and may increase the risk of major bleeding, while analysis of short time interval with person-quarter with adjustment for anti-hypertensives may reduce this bias. The high prevalence of Helicobacter pylori infection and peptic ulcer diseases in Han-Chinese population may undermine the association between gastrointestinal hemorrhage and selected medications (Nagy et al., 2016). Furthermore, DOAC and antidepressant dosage, duration and compliance were not considered in the model. The associations between bleeding risk and short-term use of medications were not identified as well. These potential misclassifications of drug exposure likely biased the results toward negative findings, and the risk of bleeding may have been underestimated. Additionally, detecting an increased bleeding risk associated with drug-drug interactions between individual DOACs and antidepressants when the number of bleeding events is small may be difficult. Exposures of multiple 
antidepressants may also affect the results, although the number is small $(0.61 \%)$. Finally, ethnic differences in bleeding risk with oral anticoagulant therapy may also limit the generalizability of our findings to other populations (Chan et al., 2016).

\section{CONCLUSION}

In conclusion, we found concurrent use of bupropion with DOACs in patients with non-valvular AF was associated with an increased risk of major bleeding, particularly in gastrointestinal hemorrhage. The combination of an DOAC and SSRIs, particularly in paroxetine, and TeCAs was associated with a higher risk of ICH. SSRIs increased the risk of ICH in the dabigatran-treated patients with AF. The combination of apixaban and SNRIs was associated with a higher risk of major bleeding. These drug-drug interactions should be carefully considered when prescribing DOACs in adult patients.

\section{DATA AVAILABILITY STATEMENT}

The original contributions presented in the study are included in the article/Supplementary Material, further inquiries can be directed to the corresponding author/s.

\section{ETHICS STATEMENT}

The studies involving human participants were reviewed and approved by the Institutional Review Board of Chang Gung Memorial Hospital, Linkou, Taiwan (ethical license no: 201901357B0). The ethics committee waived the requirement of written informed consent for participation.

\section{AUTHOR CONTRIBUTIONS}

K-HC contributed to the conceptualization, carried out the funding acquisition, investigated the data, performed the

\section{REFERENCES}

Anttila, S. A., and Leinonen, E. V. (2001). A review of the pharmacological and clinical profile of mirtazapine. CNS Drug Rev. 7, 249-264. doi: 10.1111/j.15273458.2001.tb00198.x

Caccia, S. (2007). N-dealkylation of arylpiperazine derivatives: disposition and metabolism of the 1-aryl-piperazines formed. Curr. Drug Metab. 8, 612-622. doi: 10.2174/138920007781368908

Chan, Y. H., Yen, K. C., See, L. C., Chang, S. H., Wu, L. S., Lee, H. F., et al. (2016). Cardiovascular, bleeding, and mortality risks of dabigatran in Asians with nonvalvular atrial fibrillation. Stroke 47, 441-449. doi: 10.1161/STROKEAHA. 115.011476

Chang, S. H., Chou, I. J., Yeh, Y. H., Chiou, M. J., Wen, M. S., Kuo, C. T., et al. (2017). Association between use of non-vitamin $\mathrm{K}$ oral anticoagulants with and without concurrent medications and risk of major bleeding in nonvalvular atrial fibrillation. JAMA 318, 1250-1259. doi: 10.1001/jama.2017.13883

Chen, C. C., Chen, L. S., Yen, M. F., Chen, H. H., and Liou, H. H. (2012). Geographic variation in the age- and gender-specific prevalence and incidence methodology, wrote the original draft, and reviewed and edited the manuscript. C-MC contributed to the conceptualization, investigated the data, performed the methodology, wrote the original draft, and reviewed and edited the manuscript. C-LW investigated the data, performed the methodology, and wrote the original draft. H-TT carried out the data curation, formal analysis, software, and project administration. Y-TH carried out the data curation and formal analysis, and performed the methodology. $\mathrm{H}-\mathrm{CW}$ and $\mathrm{C}-\mathrm{HC}$ investigated the data and performed the methodology. S-HC contributed to the conceptualization, carried out the funding acquisition, investigated the data, performed the methodology, supervised the data, carried out the resources, and wrote, reviewed, and edited the manuscript. All authors contributed to the article and approved the submitted version.

\section{FUNDING}

This study was financially supported by grants CFRPG3K0021 from the Chang Gung Memorial Hospital. This study was based in part on National Health Insurance Research Database data provided by the Applied Health Research Data Integration Service from National Health Insurance Administration and managed by Health and Welfare Data Science Center, Ministry of Health and Welfare. However, the interpretation and conclusions contained herein do not represent the position of Chang Gung Memorial Hospital, National Health Insurance Administration and Ministry of Health and Welfare. Chang Gung Memorial Hospital provided statistical assistance and support from the Maintenance project of the Center for Big Data Analytics and Statistics (grant CLRPG3D0043).

\section{SUPPLEMENTARY MATERIAL}

The Supplementary Material for this article can be found online at: https://www.frontiersin.org/articles/10.3389/fnagi. 2022.791285/full\#supplementary-material

of epilepsy: analysis of Taiwanese National Health Insurance-based data. Epilepsia 53, 283-290. doi: 10.1111/j.1528-1167.2011.03332.x

Cozza, K. L., Armstrong, S. C., Oesterheld, J. R., and Cozza, K. L. (2003). Concise Guide to Drug Interaction Principles for Medical Practice : Cytochrome P450s, UGTs, p-Glycoproteins. Washington, DC: American Psychiatric Pub.

Dalton, S. O., Johansen, C., Mellemkjaer, L., Norgard, B., Sorensen, H. T., and Olsen, J. H. (2003). Use of selective serotonin reuptake inhibitors and risk of upper gastrointestinal tract bleeding: a population-based cohort study. Arch. Intern. Med. 163, 59-64. doi: 10.1001/archinte.163.1.59

de Abajo, F. J., Rodriguez, L. A., and Montero, D. (1999). Association between selective serotonin reuptake inhibitors and upper gastrointestinal bleeding: population based case-control study. BMJ 319, 1106-1109. doi: 10.1136/bmj. 319.7217.1106

DeVane, C. L., Donovan, J. L., Liston, H. L., Markowitz, J. S., Cheng, K. T., Risch, S. C., et al. (2004). Comparative CYP3A4 inhibitory effects of venlafaxine, fluoxetine, sertraline, and nefazodone in healthy volunteers. J. Clin. Psychopharmacol. 24, 4-10. doi: 10.1097/01.jcp.0000104908.752 06.26 
El Husseini, N., Goldstein, L. B., Peterson, E. D., Zhao, X., Pan, W., Olson, D. M., et al. (2012). Depression and antidepressant use after stroke and transient ischemic attack. Stroke 43, 1609-1616. doi: 10.1161/STROKEAHA.111.64 3130

Gillen, R., Tennen, H., McKee, T. E., Gernert-Dott, P., and Affleck, G. (2001). Depressive symptoms and history of depression predict rehabilitation efficiency in stroke patients. Arch. Phys. Med. Rehabil. 82, 1645-1649. doi: 10.1053/apmr. 2001.26249

GmbH (2020). Pradaxa\$(Dabigatran Etaxilate). Available online at: https: //www.medicines.org.uk/emc/product/6229/smpc\#CONTRAINDICATIONS (accessed January 01, 2021).

Hackam, D. G., and Mrkobrada, M. (2012). Selective serotonin reuptake inhibitors and brain hemorrhage: a meta-analysis. Neurology 79, 1862-1865. doi: 10.1212/ WNL.0b013e318271f848

Halperin, D., and Reber, G. (2007). Influence of antidepressants on hemostasis. Dialog. Clin. Neurosci. 9, 47-59. doi: 10.31887/DCNS.2007.9.1/dhalperin

House, A., Knapp, P., Bamford, J., and Vail, A. (2001). Mortality at 12 and 24 months after stroke may be associated with depressive symptoms at 1 month. Stroke 32, 696-701. doi: 10.1161/01.str.32.3.696

Hsieh, C. Y., Chen, C. H., Li, C. Y., and Lai, M. L. (2015). Validating the diagnosis of acute ischemic stroke in a National Health Insurance claims database. J. Formos. Med. Assoc. 114, 254-259. doi: 10.1016/j.jfma.2013.09.009

Kharofa, J., Sekar, P., Haverbusch, M., Moomaw, C., Flaherty, M., Kissela, B., et al. (2007). Selective serotonin reuptake inhibitors and risk of hemorrhagic stroke. Stroke 38, 3049-3051. doi: 10.1161/STROKEAHA.107.491472

Komen, J. J., Hjemdahl, P., Mantel-Teeuwisse, A. K., Klungel, O. H., Wettermark, B., and Forslund, T. (2020). Concomitant anticoagulant and antidepressant therapy in atrial fibrillation patients and risk of stroke and bleeding. Clin. Pharmacol. Ther. 107, 287-294. doi: 10.1002/cpt.1603

Kotlyar, M., Brauer, L. H., Tracy, T. S., Hatsukami, D. K., Harris, J., Bronars, C. A., et al. (2005). Inhibition of CYP2D6 activity by bupropion. J. Clin. Psychopharmacol. 25, 226-229. doi: 10.1097/01.jcp.0000162805.46453.e3

Li, N., Wallen, N. H., Ladjevardi, M., and Hjemdahl, P. (1997). Effects of serotonin on platelet activation in whole blood. Blood Coagul. Fibrinolysis 8, 517-523. doi: 10.1097/00001721-199711000-199711006

Lip, G. Y., Nieuwlaat, R., Pisters, R., Lane, D. A., and Crijns, H. J. (2010). Refining clinical risk stratification for predicting stroke and thromboembolism in atrial fibrillation using a novel risk factor-based approach: the euro heart survey on atrial fibrillation. Chest 137, 263-272. doi: 10.1378/chest.09-1584

Lipsitch, M., Tchetgen Tchetgen, E., and Cohen, T. (2010). Negative controls: a tool for detecting confounding and bias in observational studies. Epidemiology 21, 383-388. doi: 10.1097/EDE.0b013e3181d61eeb

Loomis, C. W., and Racz, W. J. (1980). Drug interactions of amitriptyline and nortriptyline with warfarin in the rat. Res. Commun. Chem. Pathol. Pharmacol. 30, $41-58$.

Loscher, W., and Potschka, H. (2005). Drug resistance in brain diseases and the role of drug efflux transporters. Nat. Rev. Neurosci. 6, 591-602. doi: 10.1038/nrn 1728

Marchena, P. J., Tzoran, I., Brenner, B., Martín, M., Mal , R., Bura-Riviere, A., et al. (2020). Psychotropic drugs and outcome in patients receiving anticoagulant therapy for venous thromboembolism. Thromb. Haemost. 120, 620-626. doi: 10.1055/s-0040-1708482

Meijer, W. E., Heerdink, E. R., Nolen, W. A., Herings, R. M., Leufkens, H. G., and Egberts, A. C. (2004). Association of risk of abnormal bleeding with degree of serotonin reuptake inhibition by antidepressants. Arch. Intern. Med. 164, 2367-2370. doi: 10.1001/archinte.164.21.2367

Mekaj, Y. H., Mekaj, A. Y., Duci, S. B., and Miftari, E. I. (2015). New oral anticoagulants: their advantages and disadvantages compared with vitamin $\mathrm{K}$ antagonists in the prevention and treatment of patients with thromboembolic events. Ther. Clin. Risk. Manag. 11, 967-977. doi: 10.2147/TCRM.S84210

Nagy, P., Johansson, S., and Molloy-Bland, M. (2016). Systematic review of time trends in the prevalence of Helicobacter pylori infection in China and the USA. Gut Pathog. 8:8. doi: 10.1186/s13099-016-0091-97

O’Brien, F. E., Dinan, T. G., Griffin, B. T., and Cryan, J. F. (2012). Interactions between antidepressants and P-glycoprotein at the blood-brain barrier: clinical significance of in vitro and in vivo findings. Br. J. Pharmacol. 165, 289-312. doi: 10.1111/j.1476-5381.2011.01557.x
Pohjasvaara, T., Vataja, R., Leppävuori, A., Kaste, M., and Erkinjuntti, T. (2001). Depression is an independent predictor of poor long-term functional outcome post-stroke. Eur. J. Neurol. 8, 315-319. doi: 10.1046/j.1468-1331.2001.00 182.x

Rasmussen, L. H., Larsen, T. B., Graungaard, T., Skjoth, F., and Lip, G. Y. (2012). Primary and secondary prevention with new oral anticoagulant drugs for stroke prevention in atrial fibrillation: indirect comparison analysis. BMJ 345:e7097. doi: 10.1136/bmj.e7097

Reilly, P. A., Lehr, T., Haertter, S., Connolly, S. J., Yusuf, S., Eikelboom, J. W., et al. (2014). The effect of dabigatran plasma concentrations and patient characteristics on the frequency of ischemic stroke and major bleeding in atrial fibrillation patients: the RE-LY Trial (Randomized Evaluation of Long-Term Anticoagulation Therapy). J. Am. Coll. Cardiol. 63, 321-328. doi: 10.1016/j.jacc. 2013.07.104

Renoux, C., Vahey, S., Dell'Aniello, S., and Boivin, J. F. (2017). Association of selective serotonin reuptake inhibitors with the risk for spontaneous intracranial hemorrhage. JAMA Neurol. 74, 173-180. doi: 10.1001/jamaneurol. 2016.4529

Rotzinger, S., Fang, J., and Baker, G. B. (1998). Trazodone is metabolized to m-chlorophenylpiperazine by CYP3A4 from human sources. Drug Metab. Dispos. 26, 572-575.

Schalekamp, T., Klungel, O. H., Souverein, P. C., and de Boer, A. (2008). Increased bleeding risk with concurrent use of selective serotonin reuptake inhibitors and coumarins. Arch. Intern. Med. 168, 180-185. doi: 10.1001/archinternmed.20 07.32

Shehab, N., Lovegrove, M. C., Geller, A. I., Rose, K. O., Weidle, N. J., and Budnitz, D. S. (2016). US emergency department visits for outpatient adverse drug events, 2013-2014. JAMA 316, 2115-2125. doi: 10.1001/jama.2016.16201

Sheikh Rezaei, S., Mittlböck, M., Reichardt, B., and Wolzt, M. (2019). SSRI comedication with NOAC or VKA does not increase hospitalisation for bleeding: a retrospective nationwide cohort study in Austria 2010-2015. Int. J. Geriatr. Psychiatry 34, 1194-1199. doi: 10.1002/gps.5117

Sinigoj, P., Malmstrom, R. E., Vene, N., Ronquist-Nii, Y., Bozic-Mijovski, M., Pohanka, A., et al. (2015). Dabigatran concentration: variability and potential bleeding prediction in "real-life" patients with atrial fibrillation. Basic Clin. Pharmacol. Toxicol. 117, 323-329. doi: 10.1111/bcpt.12417

Skop, B. P., and Brown, T. M. (1996). Potential vascular and bleeding complications of treatment with selective serotonin reuptake inhibitors. Psychosomatics 37, 12-16. doi: 10.1016/S0033-3182(96)71592-X

Squibb, B. M. (2021). Apixaban (Eliquis). Available online at: https://www. medicines.org.uk/emc/product/2878/smpc\#INTERACTIONS (accessed May 17, 2021).

Steffel, J., Verhamme, P., Potpara, T. S., Albaladejo, P., Antz, M., Desteghe, L., et al. (2018). The 2018 European Heart Rhythm Association Practical Guide on the use of non-vitamin $\mathrm{K}$ antagonist oral anticoagulants in patients with atrial fibrillation. Eur. Heart J. 39, 1330-1393. doi: 10.1093/eurheartj/ehy136

Störmer, E., von Moltke, L. L., Perloff, M. D., and Greenblatt, D. J. (2001). Pglycoprotein interactions of nefazodone and trazodone in cell culture. J. Clin. Pharmacol. 41, 708-714. doi: 10.1177/00912700122010609

Sung, S. F., Hsieh, C. Y., Lin, H. J., Chen, Y. W., Yang, Y. H., and Li, C. Y. (2016) Validation of algorithms to identify stroke risk factors in patients with acute ischemic stroke, transient ischemic attack, or intracerebral hemorrhage in an administrative claims database. Int. J. Cardiol. 215, 277-282. doi: 10.1016/j. ijcard.2016.04.069

Tatsumi, M., Groshan, K., Blakely, R. D., and Richelson, E. (1997). Pharmacological profile of antidepressants and related compounds at human monoamine transporters. Eur. J. Pharmacol. 340, 249-258. doi: 10.1016/s0014-2999(97) 01393-1399

Verdel, B. M., Souverein, P. C., Meenks, S. D., Heerdink, E. R., Leufkens, H. G., and Egberts, T. C. (2011). Use of serotonergic drugs and the risk of bleeding. Clin. Pharmacol. Ther. 89, 89-96. doi: 10.1038/clpt.2010.240

Voican, C. S., Corruble, E., Naveau, S., and Perlemuter, G. (2014). Antidepressantinduced liver injury: a review for clinicians. Am. J. Psychiatry 171, 404-415. doi: 10.1176/appi.ajp.2013.13050709

Wang, C. L., Wu, V. C., Chang, K. H., Tu, H. T., Kuo, C. F., Huang, Y. T., et al. (2020). Assessing major bleeding risk in atrial fibrillation patients concurrently taking non-vitamin $\mathrm{K}$ antagonist oral anticoagulants and antiepileptic drugs. 
Eur. Heart J. Cardiovasc. Pharmacother. 6, 147-154. doi: 10.1093/ehjcvp/pv z035

Wang, J. S., Zhu, H. J., Gibson, B. B., Markowitz, J. S., Donovan, J. L., and DeVane, C. L. (2008). Sertraline and its metabolite desmethylsertraline, but not bupropion or its three major metabolites, have high affinity for P-glycoprotein. Biol. Pharm. Bull. 31, 231-234. doi: 10.1248/bpb. 31.231

Weiss, J., Dormann, S. M., Martin-Facklam, M., Kerpen, C. J., Ketabi-Kiyanvash, N., and Haefeli, W. E. (2003). Inhibition of P-glycoprotein by newer antidepressants. J. Pharmacol. Exp. Ther. 305, 197-204. doi: 10.1124/jpet.102. 046532

Yasui-Furukori, N., Saito, M., Niioka, T., Inoue, Y., Sato, Y., and Kaneko, S. (2007). Effect of itraconazole on pharmacokinetics of paroxetine: the role of gut transporters. Ther. Drug Monit. 29, 45-48. doi: 10.1097/FTD. 0b013e31802bb20d

Yeh, C. H., Hogg, K., and Weitz, J. I. (2015). Overview of the new oral anticoagulants: opportunities and challenges. Arterioscler. Thromb. Vasc. Biol. 35, 1056-1065. doi: 10.1161/ATVBAHA.115.303397

Zirlik, A., and Bode, C. (2017). Vitamin K antagonists: relative strengths and weaknesses vs. direct oral anticoagulants for stroke prevention in patients with atrial fibrillation. J. Thromb. Thrombolysis 43, 365-379. doi: 10.1007/s11239016-1446- 1440

Conflict of Interest: The authors declare that the research was conducted in the absence of any commercial or financial relationships that could be construed as a potential conflict of interest.

Publisher's Note: All claims expressed in this article are solely those of the authors and do not necessarily represent those of their affiliated organizations, or those of the publisher, the editors and the reviewers. Any product that may be evaluated in this article, or claim that may be made by its manufacturer, is not guaranteed or endorsed by the publisher.

Copyright (C) 2022 Chang, Chen, Wang, Tu, Huang, Wu, Chang and Chang. This is an open-access article distributed under the terms of the Creative Commons Attribution License (CC BY). The use, distribution or reproduction in other forums is permitted, provided the original author(s) and the copyright owner(s) are credited and that the original publication in this journal is cited, in accordance with accepted academic practice. No use, distribution or reproduction is permitted which does not comply with these terms. 


\section{GLOSSARY}

AF, atrial fibrillation; ARR, adjusted rate ratio; CI, confidence interval; CYP3A4, cytochrome P450 3A4; DOAC, direct oral anticoagulant; ICH, intracerebral hemorrhage; NHI, Taiwan National Health Insurance; P-gp, permeability glycoprotein; SNRI, selective serotonin-norepinephrine reuptake inhibitor; SSRI, selective serotonin reuptake inhibitors; TCA, tricyclic antidepressant; TeCA, tetracyclic antidepressant. 